\title{
A editora universitária, os livros do século XXI $e$ seus leitores
}

José Castilho Marques Neto ${ }^{1}$

A editora universitária e o mundo do livro

Cada vez mais a universidade brasileira se dá conta de que a atividade editorial acadêmica é, antes de mais nada, parte constitutiva da maturidade intelectual da instituição. Este pensamento, que se fortaleceu nos últimos anos, também evidencia que não basta publicar, mas divulgar e fazer chegar o livro às mãos do leitor, disseminando conhecimento, fazendo do livro e da revista produzidos pela Universidade parte integrante da vida do profissional que mais do que nunca precisa de formação contínua $e$ abrangente. A Editora Universitária no Brasil está tomando cada vez mais o lugar já ocupado por centenárias experiências de universidades européias: ser um forte elo entre a produção acadêmica $e$ a sociedade. Não estamos mais dialogando apenas entre pares acadêmicos, até porque não é necessário, em tempos em que impera a comunicação virtual, a universidade ter uma editora para isso. Além da circulação de idéias entre a comunidade científica, a editora universitária hoje dialoga com uma imensa gama de leitores que buscam no saber acadêmico a fonte para suas profissões $e$, porque não, para entender melhor o mundo contemporâneo.

Esta concepção de editora universitária que busca o leitor consolidou-se junto aos editores acadêmicos pela firmeza com que foi apresentada por projetos inovadores, como o da UNESP, modelo hoje seguido com grande êxito por outras universidades que procuram construir editoras profissionalizadas. Mas esta concepção de editora universitária também se impôs pelo crescimento e profissionalização do mercado editorial brasileiro. Esse mercado faturou, em 1999, R\$1.817.826.339,00, tem 400 editoras cadastradas e 1.200 livrarias ou pontos de venda de livros. Já não se trata de uma atividade artesanal, ou lúdica, numa visão mais romântica. O mercado editorial e livreiro no Brasil já é parte significativa da economia nacional, atraindo investidores e capitalistas do exterior que já adquiriram fatias

1 Professor da Faculdade de Ciências e Letras da Universidade Estadual Paulista, UNESP/Araraquara; Diretor-Presidente da Fundação Editora da UNESP e Presidente da Associação Brasileira das Editoras Universitárias (ABEU). 
expressivas deste mercado. É claro que, ao lado da pujança desses números que colocam o Brasil como oitavo produtor mundial de livros, há o contraste que aponta um consumo anual de 2,5 livros por habitante, incluindo-se neste número o livro didático, que representa quase $60 \%$ da venda de livros em circulação no Brasil.

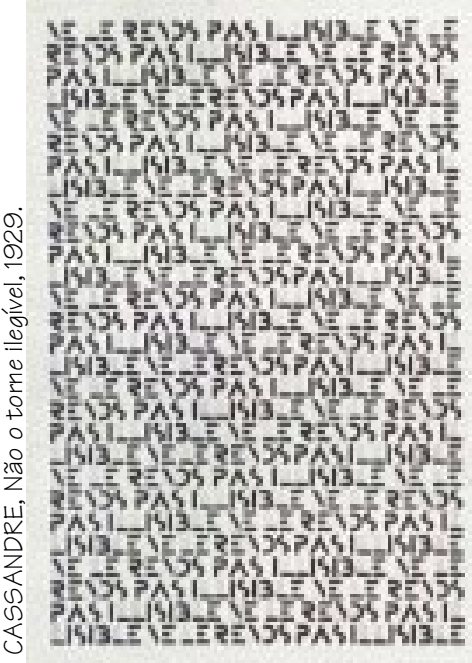

O livro "científico, técnico e profissional", conforme a nomenclatura utilizada pelo documento Diagnóstico do setor editorial brasileiro (Naves \& Oliveira, 2000), mostra que em 1999 este segmento produziu 11.654 títulos (crescimento de $10 \%$ em relação a 1998) e 20.842.864 exemplares (crescimento de $9 \%$ em relação a 1998). A mesma pesquisa aponta, ainda, que este segmento faturou $\mathrm{R} \$ 367.823 .959,00$ (-16\% rel./98) e vendeu 19.403 .417 exemplares (-9\% rel./98). As pesquisadoras do referido documento concluíram que os livros científicos, técnicos e profissionais foram os únicos que experimentaram um aumento do número de exemplares produzidos em relação ao mesmo período do ano anterior. A razão desse comportamento é assim relatada:

\footnotetext{
Este aumento buscou atender a uma demanda gerada pela mudança de comportamento por parte do consumidor, hoje interessado no aprofundamento do conhecimento de retorno prático. $\mathrm{O}$ afunilamento do mercado de trabalho, aliado à escassez de recursos, tornou imprescindível àquele que deseja garantir-se obter um nível maior de excelência. O aprofundamento dos conhecimentos, tanto em áreas específicas de atuação como na área de conhecimentos gerais tornou-se inevitável, uma vez que o próprio mercado exige uma atuação em diferentes áreas. (Naves $\mathcal{E}$ Oliveira, 2000, p.21)
}

Embora não tenhamos uma pesquisa deste tipo e abrangência exclusiva para os livros das editoras universitárias, certamente podemos afirmar que fazemos parte desse segmento "científico, técnico e profissional", não apenas pelos títulos que editamos como também pela crescente inserção das editoras acadêmicas na rede de distribuição voltada para o leitor universitário, não necessariamente aquele leitor que está nos bancos escolares. Sendo assim, uma das conclusões que se pode inferir dessas análises é a de que, não obstante as formas alternativas de distribuição dos nossos títulos, a editora da universidade deve também reforçar sua presença nos círculos de divulgação e distribuição do livro brasileiro, ampliar a possibilidade do saber universitário, atingir camadas mais amplas da população letrada e, ao mesmo tempo, lutar pela formação de novos leitores. 
Produção e disseminação de informações no livro do século XXI

Neste contexto, é importante estarmos preparados, como editores universitários, para as mudanças que já estão em marcha no mundo do livro. O discurso de pesquisadores e profissionais da área apontam para a "terceira revolução do livro". Desde a primeira revolução, marcada pelo aparecimento do livro como o conhecemos ainda hoje (o códice que substituiu os rolos da Antigüidade no século IV d. C., com suas páginas numeradas e formato revolucionário que libertou as mãos do leitor, criando uma nova relação entre o leitor e o livro), passando pela segunda revolução com a disseminação do livro impresso por Gutemberg e, finalmente, chegando ao nosso tempo com a informática e o livro eletrônico (ebook). Em futuro próximo o "papel eletrônico" se juntará aos artefatos hoje conhecidos, e todos eles organizarão de maneira diferente a relação do texto com o leitor, graças, principalmente, aos recursos do hipertexto.

A terceira revolução do livro promete, segundo as grandes corporações de informática ou os respeitáveis laboratórios do MIT que a produzem, a realização de muitas utopias que a humanidade culta desejou, como, por exemplo, a disseminação $e$ a democratização do conhecimento; a interrelação contínua entre autor e leitor (na construção de textos que quebram a barreira unilateral entre o escritor e seu leitor, que teria condições de interferir na produção autoral $e$ interagir com a criação); a criação de bibliotecas domésticas gigantes e plurais, realizando o sonho da Biblioteca de Alexandria. Essas e outras utopias estão sendo geradas pelos avanços científicos e, na visão dos analistas e produtores de novas tecnologias, são irreversíveis, a tal ponto que a gigante Microsoft prevê que em 2008 o livro eletrônico ultrapassará em vendas o livro em papel; em 2015 a biblioteca do Congresso Americano será totalmente revertida para o livro eletrônico e, em 2017, a biblioteca de livros de papel será vista como um objeto de charme antigo².

Nesta perspectiva, em que há aparentemente uma inevitabilidade da civilização da tela do computador, do triunfo das imagens e da comunicação eletrônica, cabem três perguntas, entre outras tantas que podemos formular perante o cenário atual e o do futuro próximo: 1) o livro, como o conhecemos, desaparecerá? 2) ao lado da nova tecnologia, estaremos construindo leitores? 3) qual o papel do editor (e das editoras) neste novo mundo do livro?. Reunindo as três questões do ponto de vista da universidade, caberia questionar: as universidades devem investir, ou continuar investindo, nas editoras universitárias?

À primeira questão remeto a Roger Chartier (1999), autor de A aventura do livro - do leitor ao navegador, que, em recente conferência, declarou:

...o mais provável para as décadas futuras é a coexistência, não necessariamente pacífica, das duas formas do livro e dos três modos de gravação e comunicação de textos: o manuscrito, a publicação impressa, a textualidade eletrônica. Esta hipótese é

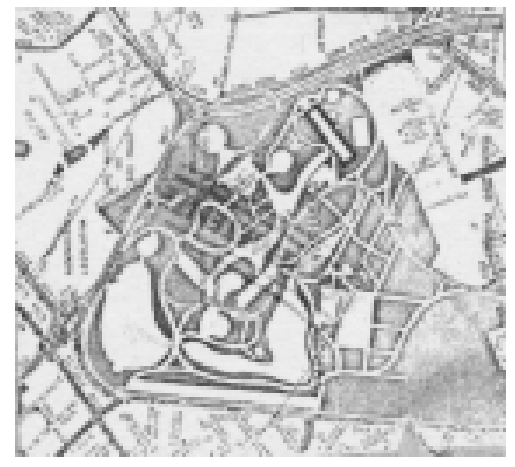

agosto, 2000 
sem dúvida mais razoável que os lamentos sobre a irremediável perda da cultura escrita ou os entusiasmos desmedidos que anunciam a entrada imediata da nova era de comunicação. (Anais do Congresso da União Internacional de Editores, 2000, p.47-8)

A segunda questão referente à formação de leitores já é mais complexa $e$ exige uma reflexão rigorosa das nossas instituições educacionais, dos governos e da sociedade civil, já que está necessariamente ligada a índices cruéis de pobreza e miséria. Se hoje encontramos muitas formas de classificar os países, não podemos mascarar os índices de pobreza da maioria deles. Segundo o insuspeito Banco Mundial, $80 \%$ da população mundial vive em zonas de pobreza, o que favorece as dificuldades da alfabetização: pobreza endógena e hereditária, baixa esperança de vida $e$ altas taxas de mortalidade infantil, desnutrição e multilingüismo. Dados como estes, analisados pela educadora Emilia Ferreiro (2000) demonstram que a humanidade adentra o século XXI com 1 bilhão de analfabetos, com o agravante de que os países considerados ricos (os 20\% restantes)

descobriram o que ela chama de "iletrados". Em que consiste esse fenômeno dos iletrados? Ferreiro nos responde que ele corresponde a uma realidade muito simples: "a escolaridade básica universal não assegura a prática cotidiana da leitura nem o gosto pela leitura nem muito menos o prazer da leitura". (Anais do Congresso da União Internacional de Editores, 2000, p.98)

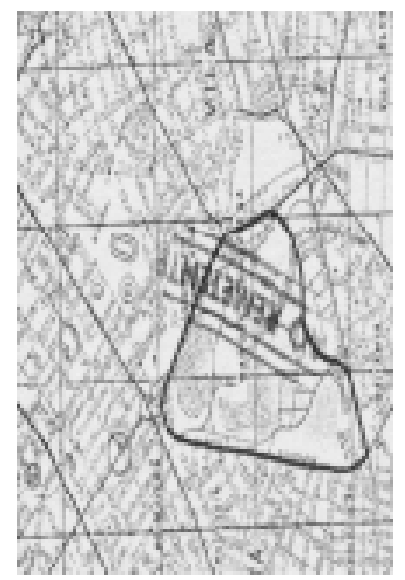

Esta análise demonstra claramente que o mundo que cria as novas tecnologias não está automaticamente produzindo alfabetizados para a vida cidadã. E cabe perfeitamente a pergunta da mesma educadora: "Se a escola não alfabetiza para a vida e o trabalho ... para que e para quem alfabetiza?". Diante dessas reflexões, cabe perguntar também: é possível seguir apostando na preservação dos valores democráticos em nossas sociedades iletradas sem fazer os esforços necessários para aumentar o número de leitores - leitores plenos, não apenas decifradores de letras? Buscar soluções arrojadas e criativas para resolver este problema, envolvendo a criação e ampliação de bibliotecas públicas e privadas abertas à comunidade, nos parece iniciativas centrais de um esforço que só terá êxito se for coletivo, e só alcançará os objetivos de formar novos leitores e disseminar informação, se contar com a vigilância cidadã dos responsáveis pela cultura em todos os níveis.

A terceira questão remete ao velho ofício de editar, essa atividade aparentemente antiquada, que trata de livros e seus conteúdos. É preciso não esquecer que um texto publicado em livro tem duas bases inalienáveis, sejam quais forem os suportes dados a esse livro: a criação editorial e a criação dos conteúdos (informativos, científicos, literários, culturais etc.). Estes são os valores reais que o leitor busca ao adquirir um livro, independentemente de onde o adquire, pela Internet ou no velho sebo do centro da cidade. O ofício de editar, que mescla funções de arte e técnica, 


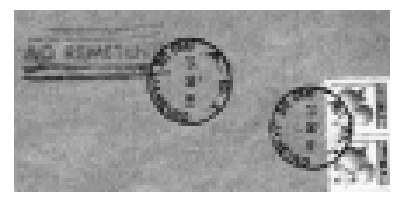

descobrindo e motivando autores, interagindo na busca do texto certo e da expressão correta e dando-lhe aspectos formais compatíveis ao conteúdo criado pelo autor são imprescindíveis e, mesmo que o livro desapareça em seu suporte atual, o que duvido, o editor continuará presente como a "alma do negócio", organizando adequadamente a avalanche de textos que chega às mãos dos leitores. É importante lembrar que o ofício do editor tem muito a ver com as atividades universitárias, já que o editor é o profissional que mais se aproxima do autor na viagem que se inicia na criação intelectual $e$ termina no leitor. É também o editor, pelas próprias características de sua profissão, um dos que mais atua na defesa dos direitos autorais e da propriedade intelectual, bem precioso dos docentes e pesquisadores, autores de nossas universidades.

\section{A universidade e sua editora}

Esta pequena reflexão em torno do mundo do livro, aponta para o quanto a universidade brasileira deve voltar-se, ou continuar voltando-se, para esta atividade. De todos os pontos de vista examinados - disseminação de conhecimentos e novas tecnologias; formação de leitores integrais, possibilitando a cidadania; função central do editor na ordenação da comunicação escrita - sempre encontramos o ensino e a pesquisa universitária vinculados a um forte setor acadêmico de publicações, interagindo e cooperando, em igualdade de condições, com editoras nacionais e internacionais.

Num país como o nosso, em que a educação básica não pode deixar de desenvolver também o conhecimento desbravador de novas fronteiras, cabe sim, às instituições de ensino superior o papel de difundir editorialmente o conhecimento. Para esta missão, a universidade tem suas editoras e centros de publicações, devendo ter sempre a preocupação de atualizá-los e incentivá-los a participar das novas e das tradicionais tecnologias.

Não é ocioso lembrar que a editora universitária, principalmente aquela ligada a universidades públicas e comunitárias, não tem fins exclusivamente comerciais. Esta condição permite a ela traçar inúmeros projetos de interesse científico ou cultural $e$, dependendo de seu projeto editorial $e$ institucional, poderá ser desde uma editora que divulgará a produção científica internacional até aquela que preservará a cultura e a produção acadêmica de uma micro região. A multiplicidade de projetos editoriais da academia, aliada à preocupação social que é inerente à atividade

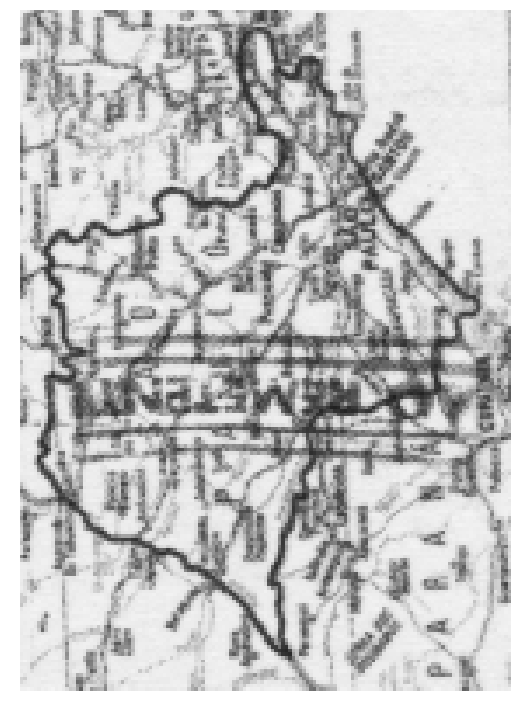


universitária, possibilita editoras fortes e peculiares em suas distintas missões.

A possibilidade de contribuir para os rumos culturais e para a difusão do conhecimento científico em nosso país, criando diálogo com outros saberes, e não dependência, talvez seja o grande elo de força entre todas as editoras universitárias brasileiras. No momento em que constatamos em muitos países da América Latina que a produção editorial, em áreas sensíveis como a da educação e a da cultura, está entregue a empresas multinacionais, cujo único objetivo é o lucro, cabe refletir se deve a universidade abrir mão de interferir positivamente, $e$ ao lado de editoras sérias e compromissadas do país, para a manutenção do saber e da cultura brasileira, que, no caso, é a preservação da própria identidade do país como nação.

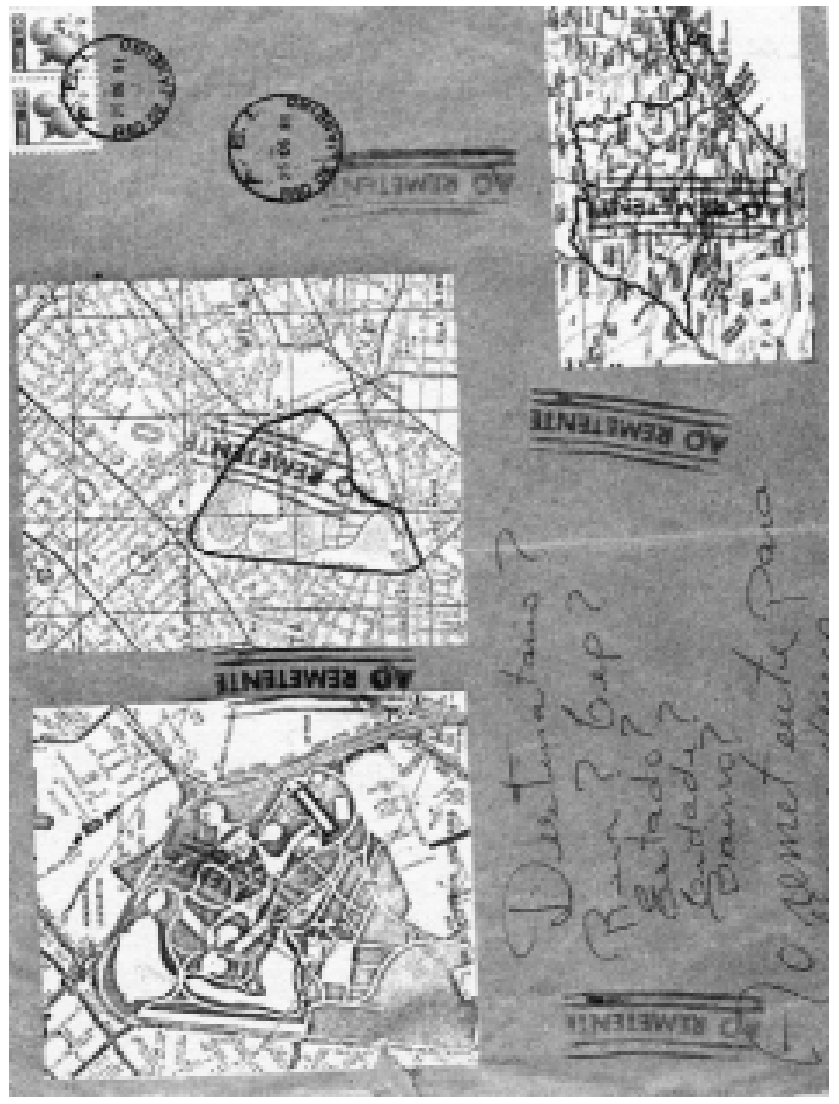

MIRIAM DANOWSKI, Arte Postal, 1981. XVI Bienal de São Paulo

\section{Referências bibliográficas}

ANAIS. Conferência no $26^{\circ}$ Congresso da União Internacional de Editores. Buenos Aires, $1^{2}$ - 4 mai. 2000.

CHARTIER, R. A aventura do livro: do leitor ao navegador. São Paulo: Editora Unesp, 1999.

FERREIRO, E. In: ANAIS. Conferência no $26^{\circ}$ Congresso da União Internacional de Editores. Buenos Aires, $1^{\circ}$ - 4 mai. 2000.

NAVES, E. M.; OLIVEIRA, M. Diagnóstico do setor editorial brasileiro. São Paulo: Câmara Brasileira do Livro, 2000.

PALAVRAS-CHAVE: Indústria editorial; livros; universidades. KEY WORDS: Book industry; books; universities.

172 Interface - Comunic, Saúde, Educ 7 